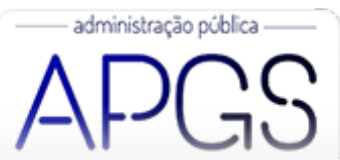

Administração Pública e Gestão Social ISSN: 2175-5787

apgs@ufv.br

Universidade Federal de Viçosa

Brasil

\title{
Fatores que impactam na qualidade do planejamento orçamentário dos municípios do estado de São Paulo
}

\author{
Andrade Speeden, Eduardo; Perez, Olivia Cristina \\ Fatores que impactam na qualidade do planejamento orçamentário dos municípios do estado de São Paulo \\ Administração Pública e Gestão Social, vol. 12, núm. 1, 2020 \\ Universidade Federal de Viçosa, Brasil \\ Disponible en: http://www.redalyc.org/articulo.oa?id=351561601004
}

Esta obra está bajo una Licencia Creative Commons Atribución-NoComercial-SinDerivar 3.0 Internacional. 


\title{
Fatores que impactam na qualidade do planejamento orçamentário dos municípios do estado de São Paulo
}

\author{
Factors that impact on the quality of budget planning in the municipalities of the state of Sao Paulo \\ Factores que impactan la calidad de la planificación presupuestaria en las ciudades del estado de Sao Paulo \\ Eduardo Andrade Speeden \\ Columbia University, Brasil \\ eduspeeden@gmail.com \\ Redalyc: http://www.redalyc.org/articulo.oa? \\ Olivia Cristina Perez \\ UFPI, Brasil \\ oliviacperez@hotmail.com \\ $\mathrm{id}=351561601004$
}

Recepción: 03 Agosto 2017

Aprobación: 10 Junio 2018

Publicación: 01 Enero 2020

\section{Resumo:}

O orçamento é um documento central da política governamental: Ele mostra quais objetivos serão priorizados no ano seguinte e no médio prazo. Este trabalho explora fatores que têm relação com a qualidade do planejamento orçamentário. A pesquisa quantitativa foi baseada no Índice de Efetividade da Gestão Municipal (IEGM) criado pelo Tribunal de Contas do Estado de São Paulo (TCESP), que mede a efetividade do planejamento nos 644 municípios do estado de São Paulo (com exceção da capital). Constatou-se que, quanto maior o município, pior a qualidade de seu planejamento orçamentário. Já o alto orçamento per capita tem efeito positivo na qualidade do planejamento. Os seguintes fatores apontados pela literatura têm baixo impacto na qualidade do orçamento: Iniciativas de transparência, existência de equipe de planejamento e controle interno formalmente instituído no município. Estes dados apontam para novas descobertas sobre o planejamento orçamentário não previstas pela literatura.

Palavras-Chave: Planejamento Orçamentário, Orçamento Público, Finanças Públicas.

\section{Resumen:}

The budget is a central document of government policy, for it shows which objectives will be prioritized the following year and in the medium term. This paper explores factors that are related to the quality of budget planning. The quantitative research was based on the Municipal Management Effectiveness Index (IEGM) created by the Court of Accounts of the State of Sao Paulo (TCESP), in Brazil, which measures the effectiveness of planning in the 644 municipalities of Sao Paulo state (except its capital). It was found that the larger the municipality, the worse the quality of its budget planning. High per capita budget has a positive effect on the quality of planning. The following factors highlighted in the literature have low impact on the quality of the budget: Transparency initiatives, existence of a budget planning team and internal control formally instituted in the municipality. These data point to new findings on budget planning not foreseen in the literature.

Palabras Clave: Planificación Presupuestaria, Presupuesto Público, Finanzas Públicas.

\section{Resumen:}

El presupuesto es un documento central de la política gubernamental: Muestra cuales objetivos se priorizarán al año siguiente y en el mediano plazo. Este artículo explora los factores que están relacionados a la calidad de la planificación del presupuesto. La investigación cuantitativa se basó en el Índice de Efectividad de Gestión Municipal (IEGM), creado por el Tribunal de Cuentas del Estado de Sao Paulo (TCESP), que mide la efectividad de la planificación en los 644 municipios del estado (excepto su capital). Se identificó que cuanto más grande es el municipio, peor es la calidad de su planificación presupuestaria. El presupuesto por persona tiene un efecto positivo en la calidad de la planificación. Los siguientes factores destacados en la literatura tienen un bajo impacto en la calidad del presupuesto: Iniciativas de transparencia, existencia de un equipo de planificación presupuestaria y control interno instituido formalmente en el municipio. Estos datos apuntan a nuevas descubiertas sobre la planificación presupuestaria no previstos en la literatura.

Palabras clave: Planificación Presupuestaria, Presupuesto Público, Finanzas Públicas. 
KEYWORDS: Budget Planning, Public Budget, Public Finance

\section{INTRODUÇÃO}

O orçamento é um documento central da política, mostrando quais objetivos serão priorizados pelos governos. Ele é considerado um dos principais instrumentos de execução da política fiscal, influenciando a economia como um todo (Dervis, 2016). A peça orçamentária deve refletir o plano de governo em seus vários programas, com informações sobre custos e resultados estimados em diversas áreas. Nela devem estar previstas, por exemplo, quantas escolas serão construídas no próximo ano, quantos leitos serão adicionados em um determinado hospital, quais as metas para reduzir a propagação de uma doença em uma dada região, etc.

A legislação orçamentária brasileira prevê que, a cada ano, o chefe do executivo deve apresentar ao Legislativo dois projetos de lei: A Lei de Diretrizes Orçamentárias (LDO) e a Lei Orçamentária Anual (LOA). A primeira fornece uma visão geral das metas e prioridades da gestão pública, enquanto a última detalha a alocação final dos recursos dos governos para o ano seguinte.

Existem diversos fatores que afetam a qualidade do planejamento orçamentário dos municípios: A transparência na gestão fiscal (Diamond, 2003; Rezende, 2011), a atuação de equipe técnica (Diamond, 2003; Santos, 2011; Azevedo, 2014), além da efetividade de instâncias de controle interno e externo (Schick, 1998; Diamond, 2003).

Detalhando melhor cada um desses fatores, primeiramente, a questão da transparência é amplamente reconhecida como fundamental para reforçar os processos de gestão e de orçamento público. Com efeito, a transparência é um fator chave na reconstrução da credibilidade das estruturas e processos de planejamento em uma sociedade democrática (Diamond, 2003; Rezende, 2011).

A falta de uma equipe técnica treinada também impacta na qualidade do planejamento orçamentário, na medida em que a gestão pública não conta com profissionais preparados para exercer funções que demandam conhecimentos específicos de legislação, contabilidade e administração. A falta de uma estrutura de planejamento pode ser, inclusive, uma das causas da imprecisão na elaboração do orçamento (Diamond, 2003; Santos, 2011; Azevedo, 2014) visto que profissionais sem preparo não conseguem cumprir a tarefa de planejamento orçamentário.

Em terceiro lugar, a ausência ou o fraco desempenho de instâncias de controle interno e externo impacta no planejamento e nas finanças municipais. As instituições de controle externo são fundamentais para a modernização do setor público, estabelecendo padrões de formalidade e de serviços nas organizações (Schick, 1998). O controle interno pode ser considerado a base para os modelos orçamentários modernos (Diamond, 2003).

Para que haja preparo da equipe técnica, transparência e controle no planejamento orçamentário, são necessários dados e estudos sobre o tema. Esta tarefa é dificultada pela falta de informações sobre o planejamento de orçamento no Brasil. Não há fontes secundárias que agreguem dados sobre os orçamentos iniciais de municípios.

A Secretaria do Tesouro Nacional possui dados sobre as execuções do orçamento de receitas e despesas, mas não sobre o planejamento inicial aprovado nas Leis Orçamentárias Anuais de cada entidade governamental. Da mesma forma, o Tribunal de Contas do Estado de São Paulo (TCESP) tem um portal da transparência com informações financeiras de todos os municípios do estado, mas não há registros de dotações orçamentárias iniciais.

No âmbito do planejamento, o que existe é o Índice de Efetividade da Gestão Municipal (IEGM), desenvolvido pelo TCESP. O IEGM foi lançado em 2015 e mede o desempenho da gestão pública em sete pilares: Educação, saúde, planejamento, meio ambiente, gestão fiscal, governança de tecnologia da informação e gestão de emergências. Cada um desses itens tem seu índice de mensuração. $\mathrm{Na}$ área do planejamento, 
o índice é chamado de iPlanejamento. Basicamente, o índice compara resultados finais do exercício com o planejamento inicial dos municípios.

Os dados relativos ao desempenho da administração pública sob a forma de índices sistemáticos foram introduzidos pela primeira vez em 2015, com base na execução orçamentária e financeira do exercício de 2014. Além de atender às necessidades técnicas do TCESP, os resultados do IEGM estão disponíveis na internet, facilitando o controle social (TCESP, 2015). Encontrar as melhores práticas na área do orçamento dentro do estado de São Paulo era praticamente impossível antes do IEGM.

Embora os resultados do IEGM estejam disponíveis no site do TCESP, não há nenhuma análise aprofundada sobre os índices, nem sobre os fatores que são mais ou menos decisivos para um bom planejamento do orçamento.

Preenchendo essa lacuna, a presente pesquisa trata do tema explorando fatores relacionados a uma boa orçamentação. A pergunta a ser respondida é: Quais são os fatores que têm relação com a qualidade do planejamento orçamentário dos municípios do estado de São Paulo? O estado tem 645 municípios, 41,9 milhões de habitantes (é o mais populoso do Brasil), produz 33,3\% do PIB nacional e é responsável por 41,4\% das receitas de impostos federais (TCESP, 2015) ${ }^{[2]}$.

Como medida da qualidade do planejamento orçamentário, partiu-se do Índice de Efetividade da Gestão Municipal (IEGM), especificamente o iPlanejamento, índice utilizado para medir o planejamento orçamentário. $\mathrm{O}$ iPlanejamento atribui notas de $\mathrm{A}$ a $\mathrm{C}$ aos municípios, conforme o nível de consistência entre o que foi planejado e o que de fato executou-se, sendo A a maior nota e C, a menor. Logo, as notas atribuídas à qualidade do planejamento orçamentário pelo iPlanejamento são usadas nesta pesquisa como referências da qualidade do planejamento orçamentário.

A pesquisa verifica o peso dos seguintes fatores apontados pela literatura na nota do planejamento orçamentário: Existência de uma equipe estruturada na área de planejamento (Diamond, 2003; Santos, 2011; Azevedo, 2014), existência de controle interno (Schick, 1998; Diamond, 2003; Azevedo, 2014) e o nível de transparência (Diamond, 2003; Rezende, 2011). Todos estes itens estão disponíveis para consulta e são utilizados no cálculo da nota do IEGM.

As primeiras manipulações de dados mostraram que municípios maiores possuíam notas do iPlanejamento piores que os municípios de menor porte. Não se trata de uma relação esperada. Em que pese a complexidade da administração orçamentária ser maior em grandes municípios, eles contam com mais recursos e infraestrutura para esta demanda. Uma equipe dedicada exclusivamente ao planejamento orçamentário, por exemplo, é mais comum em municípios de médio e grande porte do que em municípios pequenos. Percebeu-se também que os municípios com maior orçamento per capita têm melhores notas relacionadas ao planejamento orçamentário.

Por isso, afora os fatores apontados pela literatura (equipe de planejamento, controle interno e transparência), a pesquisa também mede a relação da qualidade do planejamento orçamentário com o tamanho do município (medido pelo número de habitantes) e com o orçamento per capita (resultado do orçamento executado no ano dividido pelo número de habitantes do município). Esses últimos dois fatores são hipóteses indutivas, construídas por meio da experiência.

Esta é uma pesquisa exploratória e quantitativa, com o objetivo de revelar os fatores que têm peso no desempenho do planejamento do orçamento. A análise foi realizada durante o ano de 2016 utilizando o software estatístico R.

\section{PLANEJAMENTO E ORÇAMENTO NO ÂMBITO MUNICIPAL}

A Constituição deu aos municípios certa autonomia para decidir e agir sobre assuntos de interesse local. Os municípios são responsáveis por serviços como saneamento básico, abastecimento de água, extensão das redes de esgotos e iluminação pública, prestação de serviços de saúde, educação primária e transporte público, 
serviços sociais, execução de infraestrutura urbana e construção, dentre outros (Zmitrovicks, Biscaro \& Marins, 2013).

Logo, os municípios no Brasil têm autonomia no desenvolvimento de certas ferramentas de planejamento, ainda que sob diretrizes legais federais. Por exemplo, na esfera municipal, as áreas da Saúde e Educação possuem vinculações orçamentárias importantes: De acordo com a Constituição de 1988, municípios devem aplicar pelo menos $15 \%$ da receita de impostos próprios e transferidos em ações de saúde e $25 \%$ em ações de educação. Apesar dessas vinculações, é o município que determina onde e como os recursos serão aplicados. $\mathrm{O}$ ato de legislar sobre o assunto, no entanto, é uma responsabilidade dos governos federal e estaduais.

A Carta Maior de 1988 trouxe importantes inovações no domínio da gestão das instituições do Estado. Pela primeira vez, dá-se ênfase clara ao planejamento visando o desenvolvimento nacional equilibrado. $\mathrm{O}$ artigo 165 da Constituição de 1988 estabeleceu o funcionamento do planejamento de orçamento por meio de três instrumentos hierárquicos e integrados: O Plano Plurianual (PPA), que normatiza o desempenho do governo em atividades e metas para o período de 4 anos; a Lei de Diretrizes Orçamentárias (LDO), que estabelece as prioridades para o ano seguinte; e a Lei Orçamentária Anual (LOA), que estima as receitas e define as despesas para o próximo exercício fiscal.

Além da Constituição, duas outras normas constroem a base da gestão orçamentária e financeira do setor público no Brasil: A Lei no 4320 de 1964, que determina as regras gerais de direito financeiro, e a Lei Complementar $n^{\circ} 101$ de 2000, conhecida como Lei de Responsabilidade Fiscal (LRF). A LRF estabelece limites para as despesas com pessoal, dívida e operações de crédito, prevê o desenvolvimento de metas fiscais de três anos e promove a transparência no planejamento e execução do orçamento público.

A Lei de Responsabilidade Fiscal foi um marco para o planejamento no Brasil. Logo após a estabilização da moeda e a redução das taxas de inflação, em meados da década de 1990, o Congresso aprovou a lei, que teve como objetivo reforçar o planejamento no setor público. A LRF também enfatiza o equilíbrio das contas públicas, restringindo os gastos do governo ao valor da receita. Este comando trazido pela lei inova ao criar o conceito de orçamento equilibrado autossustentável, que é obtido sem trazer dívida para o município com empréstimos, por exemplo.

No Brasil, as alterações no orçamento inicialmente aprovado ocorrem através da apropriação de créditos adicionais. Os créditos adicionais são usados quando uma alocação se revela insuficiente para a realização dos programas inicialmente previstos, ou quando há a necessidade de executar uma despesa não autorizada. Os créditos adicionais são classificados como: (1) Créditos especiais: Para as despesas para as quais não há dotação orçamentária específica, e devem ser autorizados por lei; (2) créditos extraordinários: Para despesas urgentes e não previstas, como guerra e calamidade púbica; (3) créditos suplementares: Para reforçar dotações orçamentárias (Brasil, 2016).

Segundo Azevedo (2014), embora a utilização de créditos adicionais deva ser uma exceção, os municípios estão alterando os orçamentos iniciais em altos percentuais. Nesse contexto, há bastante espaço para a informalidade na arena do orçamento: Os gestores públicos acabam por não seguir exatamente o que estava inicialmente previsto.

Em teoria, a formulação do orçamento daria condições aos gestores para executá-lo durante o ano, com poucas alterações. No entanto, muitos gestores públicos no Brasil consideram o orçamento uma "peça de ficção" por causa dos altos níveis de alteração do plano inicial.

Este contexto de informalidade permite a manutenção da disciplina fiscal, mesmo com um orçamento acima da capacidade de arrecadação de receitas do município. Os agentes responsáveis pelas finanças e orçamento têm que, formalmente - ou informalmente - , contingenciar os gastos com base no fluxo de receitas.

As estratégias de superestimação e subestimação das receitas, no momento da elaboração do orçamento, contribuem para distorções entre planejamento e execução orçamentária (Azevedo, 2014). Essas estratégias ocorrem na fase privada de preparação do orçamento. A fase privada compreende a metodologia de cálculo e 
negociações entre as agências antes da inclusão das dotações finais no projeto da LOA. Nem organismos de controle, nem a sociedade têm acesso às informações geradas nesta fase.

Como os cálculos e estimativas são informações privadas, existe baixa punição para a imprecisão orçamentária e não há prêmios para a realização de previsões com maior precisão. Logo, não há incentivos para os agentes buscarem-na em suas estimativas. A falta de incentivos diminui o interesse em investir recursos no setor de planejamento, o que leva à perpetuação de erros.

Gestores públicos usam essas estratégias para criar espaço de manobra e lidar com as pressões por recursos durante o ano. Schick (1975, p. 51, tradução nossa) fez uma boa representação das tensões que cercam os processos orçamentários: "O orçamento é um campo de batalha perene da política. Todo mundo briga. Agências brigam por mais dinheiro, unidades de orçamento para obter mais controle sobre os gastos”.

Os municípios também podem optar pela estratégia de preparação do orçamento com receitas superestimadas a fim de obter créditos orçamentários aprovados acima da capacidade efetiva de cobrança de receitas. Um possível resultado desta prática é a ocorrência de déficit orçamentário se o orçamento for executado tal como tinha sido inicialmente aprovado.

\section{FATORES QUE IMPACTAM NO PLANEJAMENTO ORÇAMENTÁRIO}

\subsection{Transparência}

Para recuperar a credibilidade em uma sociedade democrática é fundamental a transparência na elaboração e execução do orçamento. Isto significa que uma condição importante para a reconstrução do planejamento é a existência de mecanismos e instrumentos destinados a controlar a implementação de programas e projetos constantes do plano, avaliação continuada dos resultados obtidos durante o período do plano e, quando necessário, ajustes e correções para mantê-lo no caminho original (Rezende, 2011).

Os processos recentes de reforma da gestão pública têm a transparência como uma de suas principais bases. A ideia de que os dados e informações geradas pelo setor público devem ser livremente acessados pela sociedade é cada vez mais presente na visão de administradores públicos em todo o mundo. A transparência é considerada um requisito para uma boa governança. Diamond (2003) acredita que a exposição de dados força governos a modificar as políticas do passado e, por isso, tem ajudado a alcançar a disciplina fiscal e melhoria na alocação de recursos.

Portanto, haveria uma ligação direta entre a transparência e a qualidade do orçamento. $\mathrm{O}$ autor destaca que a transparência diz respeito não só à interação do governo com o legislativo e com o público, mas também aos processos e procedimentos internos para a construção de informações fiscais e sua revisão. De acordo com Diamond (2003, p. 22, tradução nossa), a transparência "é um ingrediente essencial para o estabelecimento do novo modelo de gestão do orçamento".

No Brasil, um marco recente no campo da transparência foi a aprovação da Lei de Acesso à Informação (Lei no 12.527 de 2011). A norma reforçou a transparência no governo brasileiro - como recomendado pela Constituição - criando as chamadas transparência ativa e transparência passiva. A primeira é a divulgação de informações por iniciativa da administração, garantindo fácil acesso aos cidadãos. A segunda diz respeito aos procedimentos para atender às demandas específicas dos cidadãos.

No domínio da legislação fiscal e orçamentária, a Lei de Responsabilidade Fiscal incentivou a transparência através da criação de audiências públicas obrigatórias durante a fase de formulação do planejamento e execução do orçamento.

Aliás, em termos de transparência de dados do governo, o Brasil está bem classificado em relação a outros países. No Global Open Data Index, o Brasil ocupa o $12^{\circ}$ lugar entre 122 países. A avaliação dos bancos de 
dados de gastos e do orçamento público do governo indica um nível de transparência de $70 \%$. O Brasil perde pontos nesta área porque os dados não são abertamente licenciados (Open Knowledge International, 2016).

Já no Open Budget Index 2015, o Brasil ocupa o $6^{\circ}$ lugar e pertence ao seleto grupo de quatro países juntamente com a Noruega, África do Sul e Estados Unidos - que têm pontuações mais altas em todos os três pilares de um orçamento eficiente, eficaz e accountable (International Budget Partnership, 2015).

\subsection{Equipe de Planejamento Orçamentário}

Modelos orçamentários modernos que relacionam a alocação de recursos com os planos do governo e os resultados obtidos pelas políticas públicas pressupõem a gestão e sistematização de uma enorme gama de informações. De acordo com Diamond (2003, p. 21, tradução nossa), "a modernização do setor público no sentido da orientação para o desempenho confronta custos iniciais imediatos e, com toda a probabilidade, requer injeção substancial de talento gerencial escasso para ser eficaz". O autor estabelece uma relação clara entre a qualidade do planejamento orçamentário e a existência de uma equipe qualificada para trabalhar com ele.

No mesmo sentido, Santos (2011) considera que o reforço do sistema de planejamento depende de estruturação de um corpo que tenha legitimidade e ferramentas para gerenciar o sistema, junto com agentes que tenham conhecimento do funcionamento do governo e das políticas públicas.

$\mathrm{Na}$ história recente do Brasil, sistemas de planejamento foram bastante prejudicados pelo longo período de hiperinflação na década de 1980 e início de 1990, quando as equipes de planejamento se enfraqueceram com a migração de agentes públicos qualificados para outras áreas.

A falta de uma estrutura de planejamento em entidades governamentais pode ser uma das causas da falta de precisão no orçamento (Azevedo, 2014). Existe a necessidade de uma estrutura adequada formada por recursos humanos qualificados para que ferramentas de planejamento confiáveis possam ser desenvolvidas.

\subsection{Controle Interno e Externo}

A evolução do orçamento tradicional para a adoção de técnicas mais modernas com foco em gestão e planejamento no setor público depende de instrumentos e instituições responsáveis pelo controle fiscal e orçamentário. Para Diamond (2003, p. 16, tradução nossa), "antes de tentar dar responsabilidades mais amplas para as agências na alocação de recursos, é essencial garantir que estejam operando dentro de uma estrutura de gestão financeira eficaz. Um bom controle interno é uma característica importante desta estrutura".

Nesse sentido, o controle interno "consiste em sistemas e procedimentos para garantir a conformidade com as regras e leis que protegem bens públicos; tais sistemas e procedimentos devem ser aceitos como justos, legítimos e viáveis" (Schick, 1998, p. 130, tradução nossa).

Além do controle interno, as finanças dos municípios são auditadas por instituições de controle externo, os Tribunais de Contas. Há trinta e três Tribunais de Contas no Brasil. Dentre todos eles, vinte e dois são responsáveis pelas contas dos estados e seus municípios. $\mathrm{O}$ modelo de supervisão adotado por estas instituições, no entanto, não é padronizado no país (Azevedo, 2013).

Apesar do crescente papel desses órgãos no Brasil, o foco do controle ainda é limitado à luta contra a corrupção, em especial no nível federal. Dificilmente as instituições e práticas são orientadas de forma significativa para reduzir o desperdício de recursos públicos (Azevedo, 2014). Esta falta de controle das finanças impactaria negativamente sobre seu planejamento e execução. 


\section{MATERIAL E MÉTODOS}

O Tribunal de Contas do Estado de São Paulo (TCESP) é um órgão de controle externo que atua na fiscalização contábil, financeira, orçamentária, das operações e patrimonial do estado de São Paulo e seus municípios, com exceção da capital do estado, que é auditada por Tribunal de Contas próprio (TCESP, 2015). A agência supervisiona as atividades dos órgãos públicos quanto a sua legalidade, legitimidade, economicidade, aplicação das subvenções e renúncia de receitas.

Em 2008, o TCESP começou um projeto chamado Auditoria Eletrônica dos Órgãos do estado de São Paulo (AUDESP), com o objetivo de recolher dados eletrônicos provenientes de municípios em relação a sua gestão orçamentária e fiscal. Segundo Azevedo (2013), ao longo da última década, Tribunais de Contas em todo o país iniciaram um processo de informatização das suas atividades de fiscalização. Com o tempo, os processos eletrônicos de captura e análise de dados têm evoluído, permitindo aos Tribunais realizar auditorias preliminares remotamente.

O AUDESP é uma iniciativa para o desenvolvimento do controle de gestão do governo através do uso de tecnologia da informação. O objetivo é melhorar os procedimentos de coleta de dados e informações dos órgãos fiscalizados, buscando maior flexibilidade no trabalho, o aumento da qualidade dos dados e, como resultado, o cumprimento da missão constitucional de monitorar e controlar as contas públicas do estado de São Paulo, com foco nos princípios da eficiência e eficácia. Os funcionários do TCESP envolvidos na supervisão dos municípios têm acesso a um banco de dados contendo as informações de cada órgão, em particular a sua contabilidade, com conteúdo padronizado e atualizado diretamente pelos órgãos sob supervisão (TCESP, 2015).

A informatização e padronização de dados financeiros municipais possibilitaram o surgimento de iniciativas como o Índice de Efetividade de Gestão Municipal (IEGM), que consiste em sete índices temáticos: Saúde, educação, planejamento, governança da tecnologia da informação, gestão fiscal, meio ambiente e proteção dos cidadãos. Notas foram atribuídas a cada um dos sete índices, com base em dados coletados em fontes governamentais, no sistema AUDESP e questionários preenchidos pelos municípios. Parte integrande do IEGM, o índice que mede o planejamento orçamentário, é chamado de iPlanejamento.

De acordo com o manual do IEGM (TCESP, 2015), o iPlanejamento verifica a consistência entre o que foi planejado e executado através da análise da porcentagem gerada pelo confronto dessas duas variáveis (planejamento e execução). Nesse confronto, além de aspectos relacionados ao cumprimento do que foi planejado, também é possível identificar a existência de coerência entre as metas físicas alcançadas, os recursos utilizados, os resultados obtidos pelas atividades e seus reflexos nos indicadores dos programas.

Detalhadamente, a gestão dos 644 municípios paulistas é classificada em cinco níveis: Baixo nível de adequação (nota $\mathrm{C}$ ), em fase de adequação (nota $\mathrm{C}+$ ), efetiva (nota $\mathrm{B}$ ), muito efetiva (nota $\mathrm{B}+$ ) e altamente efetiva (nota A). Para tal classificação são considerados os seguintes itens para o iPlanejamento: (1) A coerência entre os resultados dos indicadores dos programas e objetivos das atividades; (2) o confronto entre os resultados físicos obtidos pelos objetivos das atividades e os recursos financeiros utilizados; (3) porcentagem de alteração do planejamento inicial; (4) porcentagem de investimento estabelecida no planejamento inicial e executado; (5) a existência de uma equipe de planejamento do orçamento, (6) a existência de um controle interno formalmente constituído e (7) se o Diretor da Contabilidade é um servidor de carreira. Os municípios devem preencher questionários disponibilizados na internet anualmente. Em suma, o município com menor distorção entre o que foi planejado e os resultados do final do ano fiscal terá uma nota melhor. As notas atribuídas pelo iPlanejamento foram adotadas na presente pesquisa como referência para a qualidade do planejamento orçamentário.

O gráfico 1 mostra o nível de alteração da execução orçamentária em relação ao orçamento inicial dos 644 municípios pertencentes ao estado de São Paulo. 
Do mesmo gráfico se extrai a quantidade de municípios em cada uma das faixas de nota do iPlanejamento. Apenas 64 (10\%) dos municípios estão na faixa "A", enquanto outros 131 (20\%) estão na faixa "B+" e 112 (17\%) na faixa "B". Mais de 50\% dos municípios estão inseridos duas faixas inferiores: Faixa "C" (242 ou $38 \%$ dos municípios) e faixa "C +" (95 ou 15\% dos municípios).

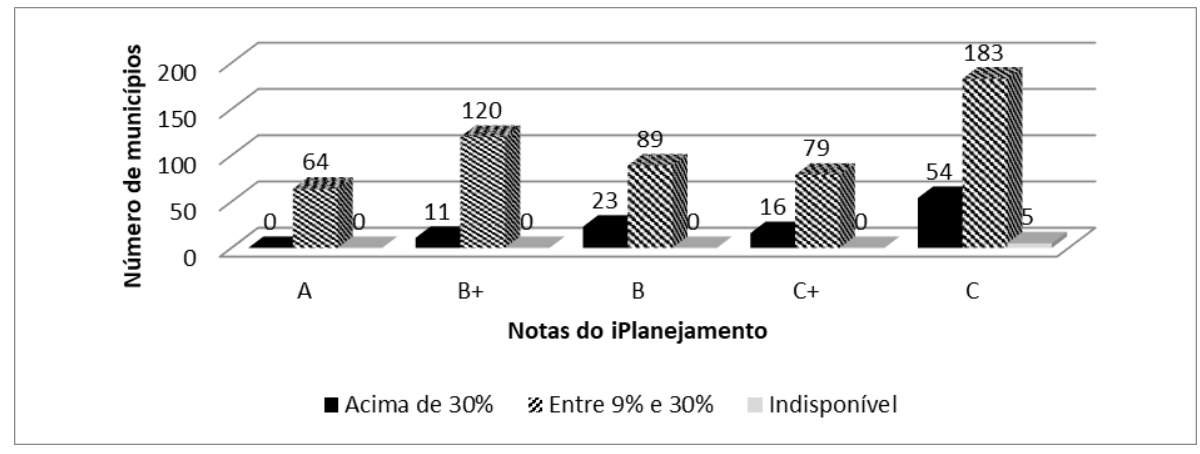

Gráfico 1 - Municípios agrupados de acordo com as notas do iPlanejamento e percentual de alteração no orçamento inicial Fonte: Elaborado pelos autores com base no IEGM/TCESP (2015).

Com relação à alteração em relação ao orçamento inicial, os dados mostram que 104 municípios alteraram seu planejamento inicial em mais de 30\%. Outros 535 municípios fizeram alterações entre 9\% e 30\% nas despesas aprovadas na Lei Orçamentária Anual. O gráfico também demonstra a relação entre o nível de alteração no orçamento e a nota do iPlanejamento. Como esperado, os municípios com maiores alterações no planejamento inicial recebem, em geral, as piores notas (considerando que um elevado nível de alteração denota pior qualidade do planejamento do orçamento).

Esses dados são importantes para visualização prévia acerca das características do universo englobado na pesquisa. Ademais, demonstram a dificuldade do planejamento orçamentário e o quanto é necessário avançar no assunto.

Na presente pesquisa, a nota atribuída pelo índice iPlanejamento foi correlacionada por meio do teste quiquadrado ${ }^{[3]}$ com os seguintes fatores apontados pela literatura: A transparência na gestão fiscal (Diamond, 2003; Rezende, 2011), a presença de uma equipe técnica qualificada (Diamond, 2003; Santos, 2011; Azevedo, 2014) e a existência de instâncias de controle interno e externo (Schick, 1998; Diamond, 2003; Azevedo, 2014).

Nota-se que dois destes itens - presença de equipe e existência de controle interno - são utilizados para compor a nota do iPlanejamento (utilizado nesta pesquisa como referência de um bom planejamento orçamentário). Logo, eles deveriam ter um peso importante no desempenho orçamentário do município. Contudo, isso não ocorreu.

Para tentar explicar então os fatores que têm relação com o bom planejamento orçamentário, foram testados dois outros itens (tamanho do município e orçamento per capita). O tamanho do município é medido pelo número de habitantes, enquanto o orçamento per capita foi calculado como resultado do orçamento executado no ano dividido pelo número de habitantes do município. Os dados para tais cálculos também estão disponíveis no IEGM/TCESP, embora não tenham sido utilizados no iPlanejamento para atribuir nota aos municípios. Estes itens foram considerados a partir da experiência com o tema e pela manipulação dos dados, momento em que surgiu uma relação explícita entre os itens. Logo, tratam-se de hipóteses indutivas construídas com a experiência prática no tema. 


\section{RESULTADOS DA PESQUISA}

\subsection{O tamanho do município}

Uma classificação importante estabelecida pelo TCESP diz respeito ao tamanho dos municípios. Dada a disparidade de seu tamanho, eles foram classificados pelo TCESP em quatro grupos, de acordo com o número de habitantes: Muito pequeno (<=5.000 habitantes), pequeno (entre 5.001 e 20.000 habitantes), médio (entre 20.001 e 200.000 habitantes), e grande (> 200.000 habitantes). Conforme este critério, dos 644 municípios paulistas, 61,6\% foram classificados pelo TCESP, em termos de tamanho, como pequeno e muito pequeno, com uma população média de 10,8 e 3,2 mil habitantes, respectivamente. Os municípios de tamanho médio e grande, por sua vez, representam $38,4 \%$ do total da população com uma população média de 59,3 e 402,3 mil habitantes, respectivamente. Os dados indicam que $80 \%$ dos municípios do estado de São Paulo têm até 50 mil habitantes. Portanto, trata-se de um conjunto predominantemente formado por municípios de menor porte.

Durante a manipulação dos dados da pesquisa, percebeu-se que essa era uma variável importante para a qualidade do planejamento orçamentário, embora a literatura não a tenha apontado.

Para analisar tal relação, os municípios foram divididos em quinze grupos, a maior parte deles formados por municípios de pequeno porte. A análise gráfica confirma a suspeita inicial de que o planejamento do orçamento foi pior classificado nos municípios maiores. O gráfico 2 mostra as linhas de tendência linear para cada faixa do iPlanejamento. A melhor e a pior nota são destacadas.

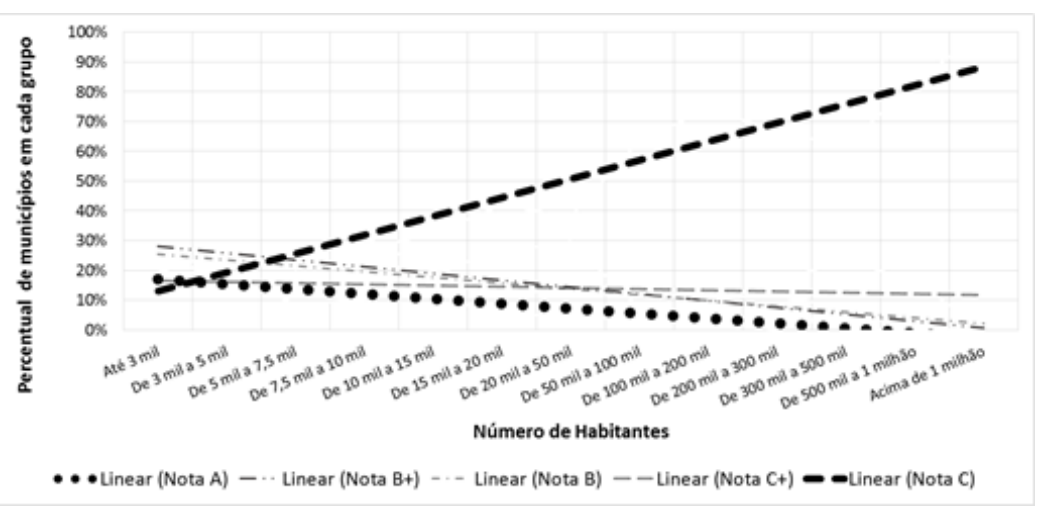

Gráfico 2 - Tendência linear da distribuição percentual das notas do iPlanejamento de acordo com o tamanho dos municípios em número de habitantes Fonte: Elaborado pelos autores com base no IEGM/TCESP (2015).

A linha de tendência pontilhada (nota "A") indica que quase $20 \%$ dos municípios com até 3 mil habitantes ganharam a pontuação máxima de TCESP. A linha decresce à medida que se desloca para a direita em municípios maiores. Ou seja, nos grupos de municípios maiores, cada vez menos deles recebem a nota máxima do TCESP. Por sua vez, a linha de tendência tracejada (nota “C”), que representa a pior nota do planejamento orçamentário, inicia-se próximo de $10 \%$ nos municípios com 3 mil habitantes, e aumenta sensivelmente para o nível de $90 \%$ nos municípios maiores.

Para comprovar tal relação foi feito o teste de Kruskal-Wallis ${ }^{[4]}$, com o auxílio do software de estatística "R", confirmando a suspeita inicial de que o tamanho de um município medido pelo número de habitantes tem relação com a qualidade do planejamento do orçamento ${ }^{[5]}$.

Em suma, a média da nota do iPlanejamento diminui à medida que cresce a média de habitantes no município. Esse resultado indica que os municípios maiores estão recebendo notas mais baixas no iPlanejamento, o que não é esperado, uma vez que os maiores municípios usualmente contam com equipes 
destinadas exclusivamente à função do planejamento, técnicos mais qualificados, sistemas informatizados integrados de planejamento e orçamento, entre outros. O resultado mostra que municípios grandes, a despeito de possuírem mais recursos e infraestrutura, enfrentam mais dificuldades no seu planejamento orçamentário.

\subsection{Orçamento per capita}

Outra suspeita levantada na manipulação dos dados foi a de que as maiores notas do iPlanejamento têm relação com o orçamento executado per capita. Essa explicação, assim como a relacionada ao tamanho dos municípios, não foi apontada pela literatura. Mesmo assim, optou-se pela verificação do orçamento per capita calculado como resultado do orçamento executado no ano dividido pelo número de habitantes do município.

Para o cálculo, os municípios foram divididos em quatorze grupos iguais com quarenta e seis cidades cada um a partir do menor para o maior orçamento executado em 2014. Cada grupo é representado pela média do orçamento executado per capita. O gráfico 3 apresenta as notas do iPlanejamento com as notas (A, B +, $\mathrm{B}, \mathrm{C}+\mathrm{e} \mathrm{C}$ ) no eixo y e o orçamento executado per capita no eixo $\mathrm{x}$. Dessa forma, quanto menor o valor no eixo y, melhor a qualidade do planejamento orçamentário.

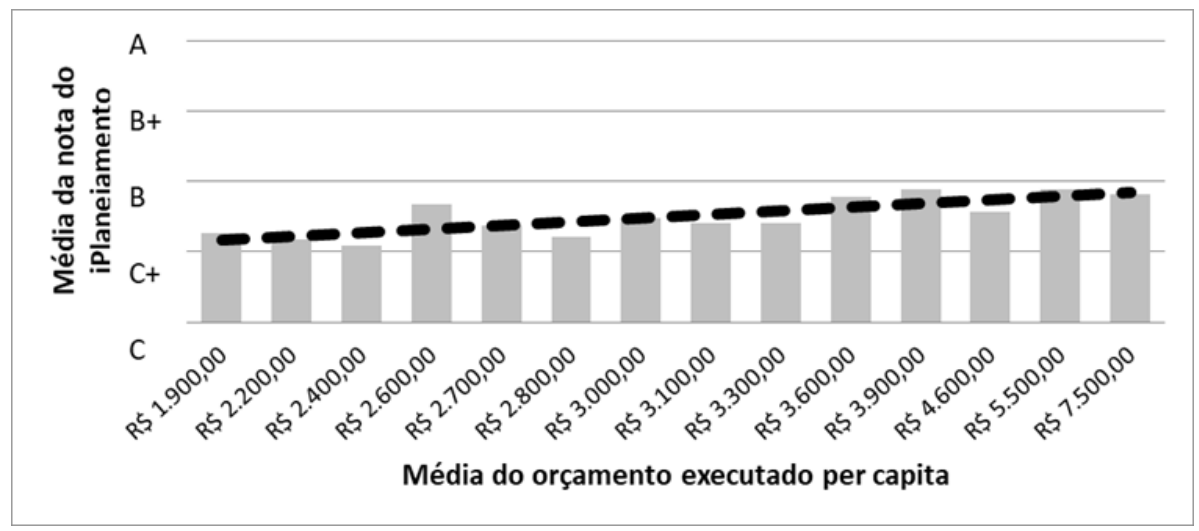

Gráfico 3 - Evolução do iPlanejamentode acordo com o crescimento da média do orçamento executado per capita

Fonte: Elaborado pelos autores com base no IEGM/TCESP (2015).

A linha de tendência mostra que quanto maior o orçamento médio per capita executado (eixo $\mathrm{x}$ ), melhor a média de qualidade do planejamento do orçamento de um município. Parte-se de uma nota média próxima de "C+" em municípios com orçamento per capita médio de $\mathrm{R} \$ 1.900,00$ para uma nota média próxima de " $\mathrm{B}$ " em municípios com orçamento per capita médio de $\mathrm{R} \$ 7.500,00$. O teste do qui-quadrado confirmou a relação entre as variáveis orçamento per capita e nota do iPlanejamento ${ }^{[6]}$.

Os dados revelam que a nota do iPlanejamento melhora à medida que o orçamento per capita médio sobe. Municípios com maior orçamento per capita, em tese, possuem mais recursos para aplicar nos serviços públicos e investimentos.

Ressalta-se que aqui o tamanho do município não está exercendo influência, uma vez que o objetivo da análise do orçamento per capita é justamente tirar o tamanho do município da equação, na medida em que o orçamento é dividido pelo número de habitantes. 


\subsection{Existência de equipe de planejamento orçamentário}

Diamond (2003), Santos (2011) e Azevedo (2014) compartilham a opinião de que o sucesso de técnicas orçamentárias modernas depende de equipes talentosas envolvidas na sua implementação e gestão.

Um dos itens que compõem o índice iPlanejamento é a existência de uma equipe estruturada responsável pela formulação das leis de planejamento do orçamento municipal (PPA, LDO e LOA). Cada município respondeu "sim" ou "não" à pergunta. Tais dados estão sistematizados no gráfico 4.

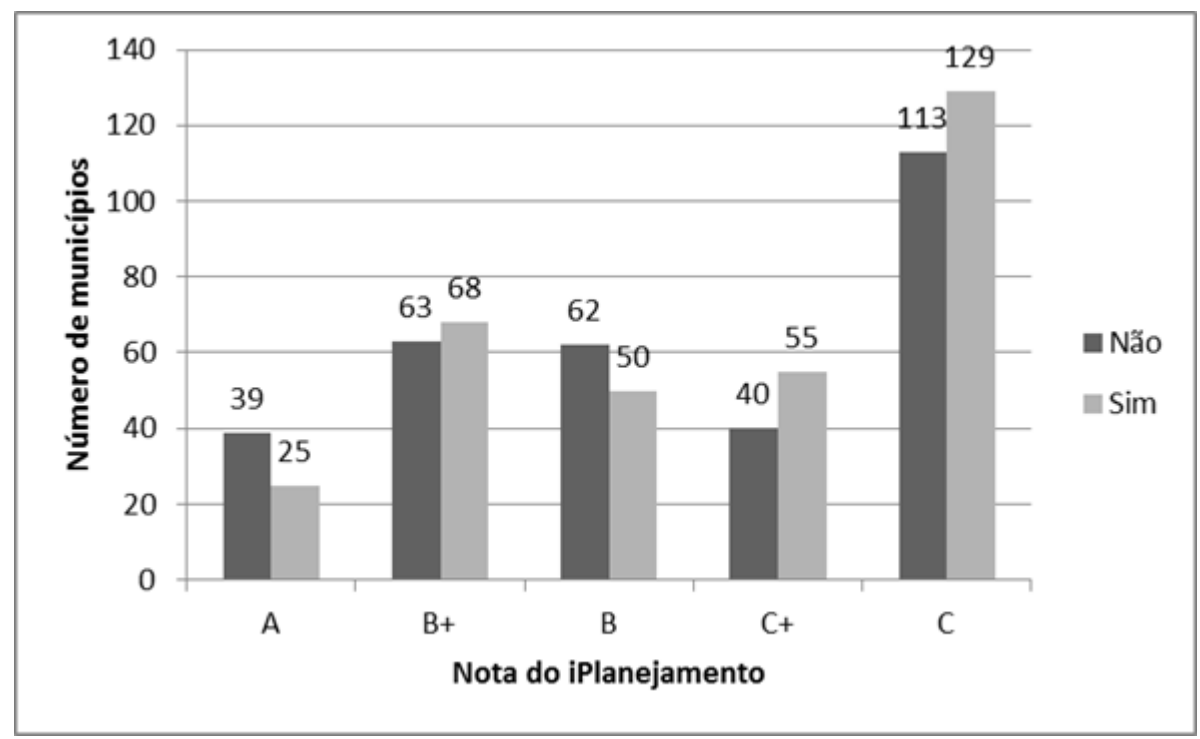

Gráfico 4 - Relação entre existência de uma equipe de planejamento orçamentário e notas do iPlanejamento Fonte: Elaborado pelos autores com base no IEGM/TCESP (2015).

O gráfico 4 apresenta um resultado bastante equilibrado: Dos 644 municípios, 327 (um pouco mais da metade) têm uma equipe de planejamento do orçamento estruturada. Além disso, o resultado também é equilibrado em cada faixa do iPlanejamento.

Contudo, na faixa "A", 39 municípios (ou 60\% do total) declararam não ter uma equipe de planejamento do orçamento. Isso parece um contrassenso, já que a maior nota deveria estar relacionada à existência de uma equipe de planejamento.

Para verificar a relação entre a existência da equipe de planejamento e a nota do iPlanejamento, foi realizado o teste do qui-quadrado. O resultado, porém, não mostrou significância para essa variável ${ }^{[7]}$, indicando que a equipe não é determinante para a qualidade do planejamento orçamentário.

Para tentar entender esse resultado, levantou-se a hipótese, já apontada no item 4.1 deste trabalho, de que o que importa é o tamanho do município. No sentido de demonstrar essa relação, comparou-se a nota do iPlanejamento com a presença de equipe de planejamento, atentando para o tamanho do município. 


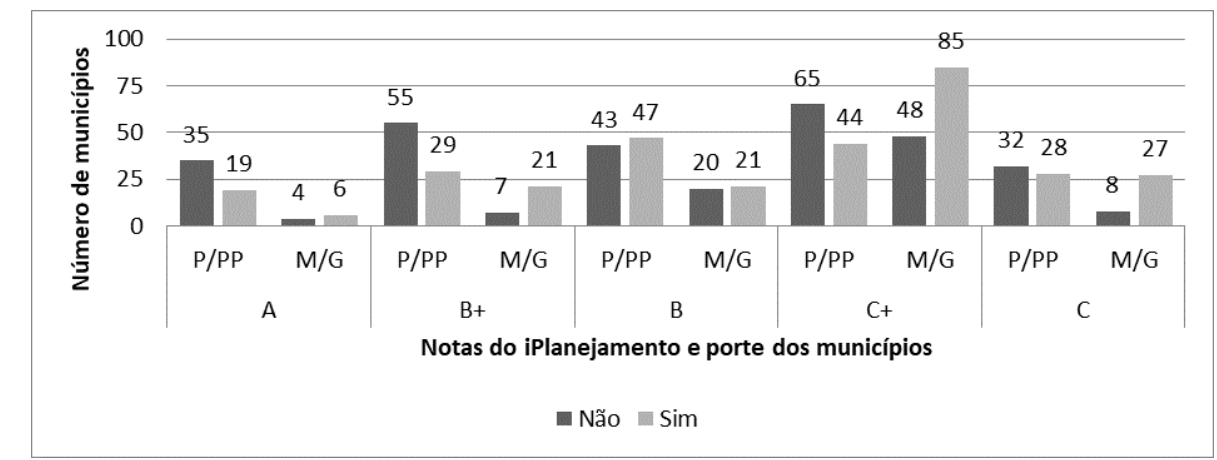

Gráfico 5 - Relação entre existência de uma equipe de planejamento orçamentário e notas do iPlanejamento considerando o tamanho do município Fonte: Elaborado pelos autores com base no IEGM/TCESP (2015).

Nota-se que a maioria dos municípios de tamanho muito pequeno (PP) e pequeno (P) não possui equipe de planejamento, independente da faixa de nota do iPlanejamento (exceto na faixa B). Já a maioria dos municípios de tamanho médio $(\mathrm{M})$ e grande $(\mathrm{G})$ conta com equipe de planejamento.

É compreensível que os pequenos municípios não possuam uma equipe dedicada ao planejamento do orçamento. Na maioria dos casos, o(a) contador(a) acaba acumulando essa função. A questão é: Por quê os maiores municípios com equipes não estão atingindo as melhores notas? Este é um resultado inesperado, dada a importância de se ter uma equipe responsável pela elaboração do planejamento orçamentário, conforme Diamond (2003) e Schick (1998).

Um olhar mais atento à qualidade da equipe pode ser necessário para entender esse resultado, uma vez que uma equipe mal preparada e desmotivada não será capaz de elevar a qualidade do orçamento. Outro aspecto importante a ser avaliado é a força relativa do setor de planejamento dentro do governo e quão perto esse setor está do núcleo do governo, onde as decisões estratégicas são tomadas.

\subsection{Existência de controle interno formalmente estabelecido}

O controle interno é o órgão que faz a mediação entre o município e o Tribunal de Contas. Ele é considerado pelo TCESP como fundamental, não só para o planejamento, mas também para a administração municipal como um todo.

A existência de controle interno tem como base a Lei no 4.320/64, a Lei de Responsabilidade Fiscal, e a Lei Orgânica do TCESP. O TCESP emitiu norma em setembro de 2012 (Comunicado SDG n 32), ordenando a imediata regulamentação do controle interno municipal, cuja equipe deve ser formada por servidores de carreira.

O avanço do controle interno abre a possibilidade de conceder aos gestores mais liberdade e responsabilidade de alocar recursos e adotar um sistema de orçamento mais moderno com foco na gestão e em resultados (Schick, 1998; Diamond, 2003). A existência do controle interno nos municípios do estado de São Paulo foi verificada pelo IEGM e os dados do gráfico 6 trazem esta informação. 


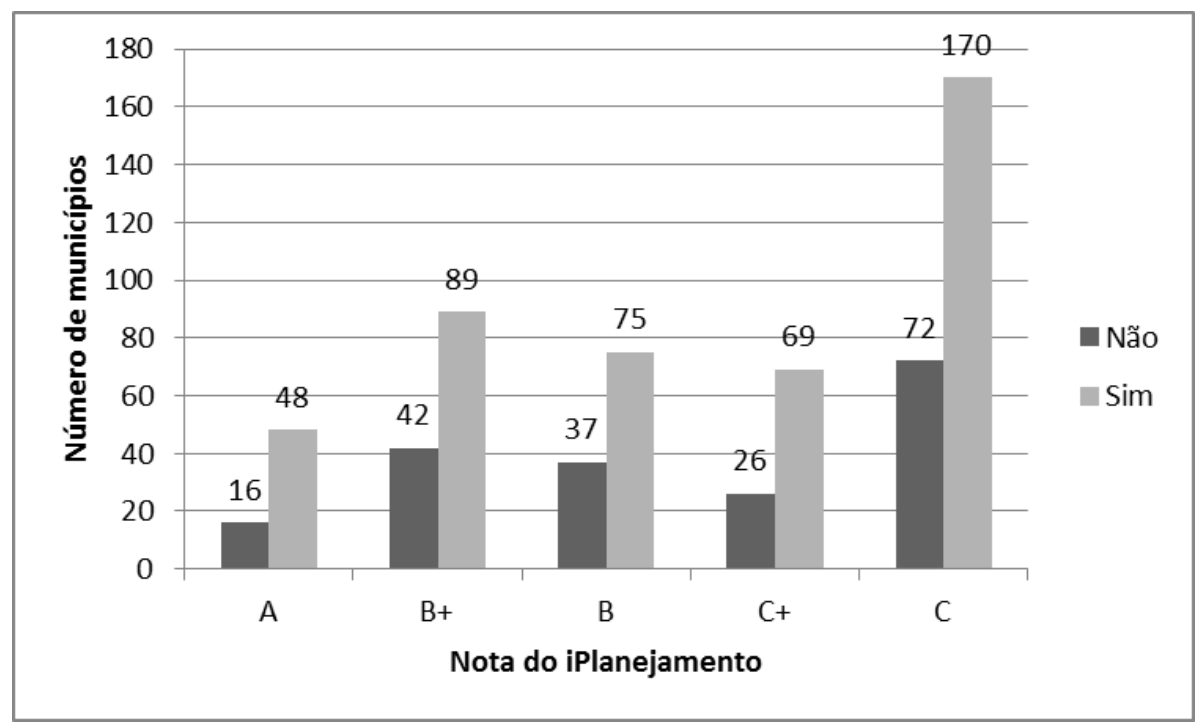

Gráfico 6 - Municípios agrupados de acordo com as notas do iPlanejamento e a existência de órgão ou servidor responsável pelo controle interno Fonte: Elaborado pelos autores com base no IEGM/TCESP (2015).

Diferente dos resultados acerca da existência de equipe de planejamento, 451 municípios, ou seja, 70\% deles, têm órgão ou servidor responsável pelo controle interno. Este é um dado positivo, principalmente quando se considera que as instituições de controle interno são fundamentais para a modernização do setor público, estabelecendo as bases para os padrões de formalidade e de serviços nas organizações (Schick, 1998; Diamond, 2003).

No entanto, a existência de controle interno formalmente estabelecido pela entidade não é um fator determinante para a qualidade no planejamento medida pelo iPlanejamento. $\mathrm{O}$ teste do qui-quadrado não mostrou relação significativa entre estas variáveis ${ }^{[8]}$.

Uma possível explicação dada por Azevedo (2014) é que o controle interno se concentra atualmente sobre a execução orçamentária em detrimento do planejamento orçamentário. $\mathrm{O}$ autor chama a atenção para dois outros fatores: Em primeiro lugar, as informações criadas e recolhidas pelo controle interno não chegam ao setor de planejamento; em segundo lugar, o foco do controle interno é orientado ao combate à corrupção, ao invés do uso eficiente dos recursos.

À semelhança do que foi encontrado nos dados sobre a existência de uma equipe de planejamento, a maioria dos municípios que não têm controles internos formalmente estabelecidos é pequeno. Dos 193 municípios que responderam "não", 123 pertencem aos grupos $\mathrm{PP}$ e $\mathrm{P}$, e 70 pertencem aos grupos M e G.

\subsection{Transparência na gestão fiscal}

A transparência foi medida pelo TCESP especificamente quanto à publicação na internet de informações sobre o planejamento do orçamento, execução orçamentária e cobrança de impostos, podendo ter esta divulgação de modo parcial. O gráfico 7 apresenta dados sobre tal divulgação, agrupando os municípios segundo as notas obtidas no iPlanejamento. 


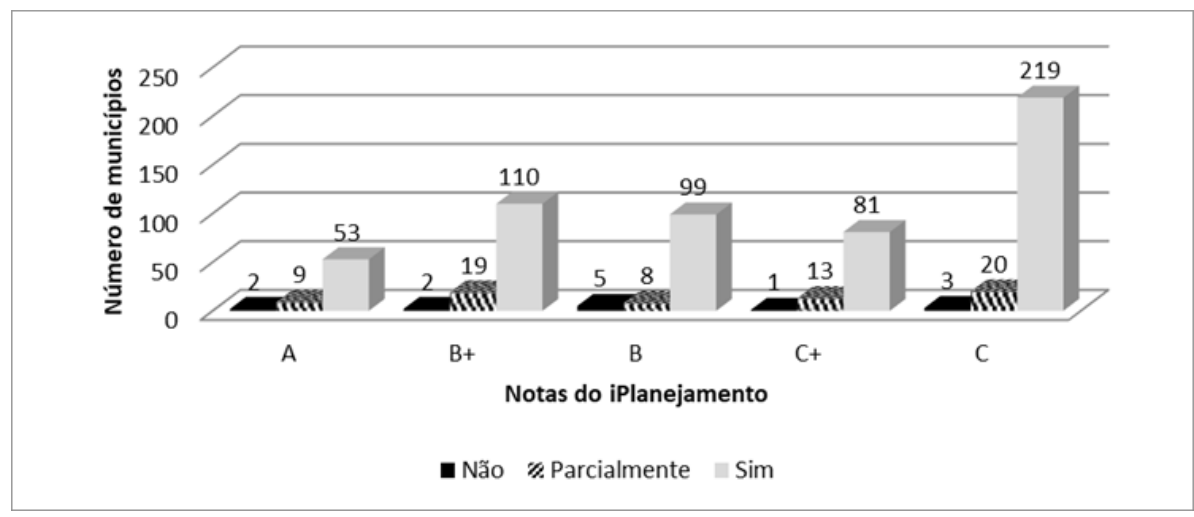

Gráfico 7 - Municípios agrupados de acordo com as notas do iPlanejamento e transparência na gestão fiscal Fonte: Elaborado pelos autores com base no IEGM/TCESP (2015).

O gráfico 7 retrata o fato de que 562 municípios (ou 87\% do total) no estado de São Paulo publicam informações sobre a gestão financeira na internet. Apenas 13 municípios não fazem qualquer tipo de publicação e 69 publicam seus dados parcialmente. O TCESP não detalha o que foi considerado como "parcialmente" na divulgação de informações de gestão fiscal na internet.

Apesar da importância das iniciativas de transparência como pré-condições para a boa governança (Diamond, 2003; Rezende, 2011), a análise estatística através do teste qui-quadrado não mostrou relação significativa entre as variáveis de transparência e qualidade do planejamento.[9]Desta forma, é necessário verificar a existência de processos e procedimentos internos no âmbito das entidades para a utilização das informações fornecidas para enriquecer o planejamento do orçamento. Pode ser que as informações estejam disponíveis somente para cumprir a legislação e que não estão sendo utilizadas internamente. (Error 38: La referencia Rezende, 2011 debe estar ligada) (Error 39: El tipo de referencia Rezende, 2011 es un elemento obligatorio) (Error 40: No existe una URL relacionada)

\section{CONCLUSÃO}

As dificuldades do planejamento orçamentário brasileiro são enormes. Por um lado, governos preparam orçamentos para além da sua capacidade de arrecadação de receitas e, em seguida, formalmente - ou informalmente - contingenciam gastos e adiam projetos para alcançar o equilíbrio fiscal no final do exercício. Por outro lado, orçamentos são fortemente alterados, quer pela apropriação do excesso de arrecadação, revelando uma subestimação da previsão de receita, quer pela alta taxa de realocação de recursos entre os programas. Nota-se que este não trata apenas de erros de previsão de orçamento, mas também de estratégias deliberadas, adotadas por gestores públicos para administrar os recursos durante o ano.

Estando os autores cientes de tais problemas, este estudo procurou contribuir com o conhecimento, ainda escasso, sobre o orçamento público no Brasil, analisando as notas referentes ao planejamento orçamentário (iPlanejamento) estabelecidas pelo Índice de Efetividade da Gestão Municipal (IEGM), desenvolvido pelo Tribunal de Contas do Estado de São Paulo (TCESP). As notas atribuídas ao planejamento orçamentário são referentes aos 644 municípios do estado de São Paulo (com execeção da capital). O objetivo foi verificar os fatores que influenciam a qualidade da orçamentação.

A literatura indica a importância da transparência (Diamond, 2003; Rezende, 2011), a presença de uma equipe técnica qualificada (Diamond, 2003; Santos, 2011; Azevedo, 2014), bem como a existência de instâncias de controle (Schick, 1998; Diamond, 2003; Azevedo, 2014). No entanto, nenhuma associação foi identificada entre essas variáveis e a qualidade do planejamento orçamentário. 
De acordo com os resultados do IEGM, apenas 64 municípios (9,9\% do total) tiveram nota "A" no Índice de Planejamento. Nesta pesquisa verificou-se que, quanto maior o município, pior é a qualidade do planejamento orçamentário. Já o orçamento per capita tem um efeito positivo sobre a nota do iPlanejamento. Quanto maior o orçamento per capita médio, maior a qualidade do planejamento orçamentário do município. Ou seja, presentes essas duas condições (ser pequeno e com alto orçamento, proporcional ao número de habitantes), a qualidade do planejamento orçamentário sobe. Estes resultados (separados ou combinados) não são mencionados pela literatura, por isso eles são ainda mais importantes: Apontam uma combinação de condições novas para o bom planejamento orçamentário.

Para futuras investigações, é necessário e salutar que o TCESP (responsável pela elaboração de IEGM) promova maior detalhamento das variáveis, como a distorção das receitas e das despesas, o percentual de alteração do orçamento inicial, entre outros. Os agrupamentos atuais dos dados são demasiadamente abrangentes, impedindo uma maior diferenciação entre os municípios.

Os dados sobre as despesas correntes e de capital, receitas próprias e transferidastambém seriam úteis para uma análise mais aprofundada. Um banco de dados mais completo e detalhado (incluindo novas variáveis qualitativas em relação à estrutura e processos de orçamentação) pode se tornar importante fonte de informações para estudos do setor público brasileiro.

Ademais, a ampliação do horizonte temporal e do número de municípios comparados em pesquisas como esta vai contribuir para um melhor entendimento do processo de planejamento no setor público brasileiro e seu consequente e necessário fortalecimento.

\section{REFERÊNCIAS}

Azevedo, R. Imprecisão na estimação orçamentária dos municípios brasileiros. Dissertação (Mestrado), (2014). Ribeirão Preto: Faculdade de Economia, Administração e Contabilidade de Ribeirão Preto.

Azevedo, R. (2013). Uma análise dos índices da lei de responsabilidade fiscal nos municípios paulistas após a implantação do Projeto Audesp. Revista de Gestão, Finanças e Contabilidade. Salvador, v. 3, n. 2, p. 39-60.

Brasil (2016). Manual técnico de orçamento MTO. Brasília: Ministério do Planejamento, Orçamento e Gestão.

Dervis, K. (2016). Global Trends as Backgrounds for Global Governance Issues. Course of Global Economic Governance, Week 1, Module 2 (video), Global Executive Masters in Public Administration, Columbia University,

Diamond, J. (2003) From program to performance budgeting: the challenge for emerging market economies. IMF Working Paper. Fiscal Affairs Department, p. 03-26. Disponível em: http://www.imf.org/external/pubs/ft/ wp/2003/wp03169.pdf. Acessado em Jun 2016.

International Budget Partnership (2015). Open Budget Survey 2015. Open Budgets Transform Lives. Disponível em: < http://www.internationalbudget.org/wp-content/uploads/OBS2015-Report-English.pdf > Acessado em Jul 2016..

OECD (2014). Draft Recommendation of the OECD Council on the Principles of Budgetary Governance. Public Governance And Territorial Development. OECD Senior Budget Officials.

OECD. OECD Best Practices for Budget Transparency (2002). Disponível em: < https://www.oecd.org/gov/budgeting/Best\%20Practices\%20Budget\%20Transparency\%20-\%20complete \%20with\%20cover\%20page.pdf>. Acessado em Jun 2016.

Open Knowledge International. Open Data Index (2016). Disponível em: http://index.okfn.org/ . Acessado em Jul 2016.

Rezende, F. (2011). Planejamento no Brasil: auge, declínio e caminhos para a reconstrução. In: Cardoso Jr, J. (org.). A reinvenção do planejamento governamental no Brasil. Brasília: Ipea, p. 177-216.

Santos, E. (2011). O Confronto entre o Planejamento Governamental e o PPA. In: Cardoso Jr, J. C. (org.). A reinvenção do planejamento governamental no Brasil. Brasília: Ipea, 2011. p. 307-336. 
Schick, A. (1975). The Battle of the Budget. Proceedings of the Academy of Political Science, Vol. 32, No. 1. The Academy of Political Science, pp. 51-70.

Schick, A. (1998). Why Most Developing Countries Should Not Try New Zealand Reforms. The World Bank Research Observer, vol. 13. p. 123-131.

TCESP (2015). Índice de Efetividade da Gestão Municipal. São Paulo, TCE. Disponível em: https:// www4.tce.sp.gov.br/sites/tcesp/files/manual-iegm-tcesp_0_0.pdf. Aceesado em Jan 2016.

TCESP (2015). 2013. Manual Básico: O Controle Interno do Município. São Paulo, TCE, Setembro. Disponível em: http://www4.tce.sp.gov.br/sites/default/files/manual-basico-controle-interno-do-municipio.pdf. Acessado em Jul 2016

Zmitrowicz, W.; Biscaro, C.; Marins, K. (2013).A organização administrativa do município e o orçamento municipal. São Paulo: EPUSP.

\section{Notas}

[1] Uma versão dessa pesquisa foi apresentada como trabalho final no curso de mestrado profissional em Administração Pública na Universidade de Columbia, em Nova Iorque, Estados Unidos.

[2] O estado de São Paulo conta com 645 municípios contando com a capital. No entanto, o escopo da presente pesquisa são os 644 municípios, uma vez que a capital conta com Tribunal de Contas próprio, por isso não é englobada nos dados do Tribunal de Contas do Estado (base para a presente pesquisa).

[3] O teste do qui-quadrado para independência é um teste não paramétrico para avaliar a associação entre as variáveis qualitativas. Seu princípio básico é o de comparar possíveis diferenças entre as frequências observadas e esperadas para um determinado evento. Portanto, pode-se dizer que dois grupos se comportam de um modo semelhante se as diferenças entre as frequências observadas e esperadas em cada categoria são muito pequenas, próximo de zero.

[4] Kruskal-Wallis é um teste não paramétrico utilizado para comparar três ou mais populações. Ele serve para testar a hipótese nula de que não existem diferenças entre os grupos, contra a hipótese alternativa de que os grupos não são os mesmos. $\mathrm{O}$ teste foi realizado para examinar a relação entre iPlanejamento e número de habitantes dos municípios.

[5] A relação entre essas variáveis foi significativa, $\mathrm{X} 2(2, \mathrm{~N}=644)=78,62, \mathrm{P}<0,001$.

[6] A relação entre essas variáveis foi significativa, $\mathrm{X} 2(2, \mathrm{~N}=644)=70,72, \mathrm{P}<0,05$.

[7] No teste qui-quadrado, em relação à questão "Existe equipe estruturada para a realização do planejamento municipal (PPA, LDO e LOA)?". O resultado foi: $\mathrm{x}=7,81$; P-value $>0,05$.

[8] No teste qui-quadrado, em relação à questão "Existe órgão ou servidor responsável pelo controle interno no município com atribuições formalmente definidas?”. O resultado foi: $x=1,84$; P-value $>0,05$.

[9] No teste qui-quadrado, em relação à questão "Os dados relativos à transparência na gestão fiscal (planejamento, execução orçamentária, arrecadação de impostos) são publicados na internet?”. O resultado foi: x=11,58; P-value >0,05.

\section{BY-NC-ND}

